\title{
The Role of Water Chemistry for Environ- mentally Assisted Cracking in Low-Alloy Reactor Pressure Vessel and Piping Steels under Boiling Water Reactor Conditions
}

\author{
Hans-Peter Seifert* and Stefan Ritter
}

\begin{abstract}
The environmentally assisted initiation and propagation of cracks in structural materials is one of the most important degradation and ageing mechanisms in light water reactors (LWR) and may seriously affect plant availability and economics. In the first part of this paper a short general introduction on environmentally assisted cracking (EAC) and its significance for LWR is given. Then the important role of water chemistry control in reducing the EAC risk in LWR is illustrated by current research results about the effect of chloride transients and hydrogen water chemistry on the EAC crack growth behaviour of low-alloy reactor pressure vessel and piping steels under boiling water reactor conditions.
\end{abstract}

Keywords: Boiling water reactor · Environmentally assisted cracking $\cdot$ Reactor pressure vessel $\cdot$ Water chemistry

\section{Introduction}

Environmentally assisted cracking (EAC) is a term to describe service failures in engineering materials that occur by environmentally induced slow crack propagation. EAC initiation and growth in structural materials are caused by the combined and synergistic interaction of corrosion reactions in the service environment and the operational thermo-mechanical loads and/or residual stresses. EAC covers a continuous spectrum from stress corrosion cracking (SCC) under static loading to corrosion fatigue (CF) under distinct cyclic loading conditions and is controlled by environmental, material, and

\footnotetext{
${ }^{*}$ Correspondence: H.P. Seifert
}

Labor für Werkstoffverhalten (LWV)

Forschungsbereich Nukleare Energie und Sicherheit (NES)

Paul Scherrer Institut (PSI)

$\mathrm{CH}-5232$ Villigen PSI

Tel.: +4156310 4402

Fax: +41563102199

E-Mail: hans-peter.seifert@psi.ch loading parameters. EAC cracks generally initiate from small surface discontinuities (e.g. slip steps, machining markings, weld defects, inclusions) that pre-exist or are formed during service by corrosion (e.g. pitting), wear or other processes. They propagate with little outside evidence of both corrosion and macroscopic deformation and therefore with no early warning as component failure approaches. Crack openings and the plastic deformation associated with crack propagation may be so small that cracks are virtually invisible except in special non-destructive examinations [1].

The ageing of light water reactors (LWR) has given rise to many material corrosion problems of which EAC has proved to be one of the most serious. EAC cracking incidents have occurred in both boiling water (BWR) and pressurized water reactors (PWR) in a wide range of stainless steel, nickel-base alloy, carbon and low-alloy steel components, such as reactor internals (core shroud, reactor pressure vessel head penetrations, springs and bolts), pressure vessels (reactor pressure vessel and steam generator nozzles, feedwater tanks, deaerators), pipings/tubings (BWR reactor water clean-up system, steam generator heat exchanger) and turbine discs. EAC may seriously affect plant availability/economics (e.g. by extended shut-down periods for component repair or replacement, maintenance programmes), periodic in-service in- spection (e.g. reduced inspection intervals), lifetime (extension) and in severe cases even safety [2-4].

To avoid the (re-)occurrence of such cracking incidents and to ensure safe and economic operation, it is essential to identify those system conditions and combinations of material, environmental and loading parameters which may lead to EAC initiation and growth and to identify the major factors of influence. Reliable quantitative experimental data on EAC initiation and growth under different LWR operation conditions and a basic knowledge of the underlying mechanisms are essential to evaluate the possible effects of EAC on structural integrity/safety and lifetime of components and to define and qualify possible material-, operation- or design-related mitigation, repair and maintenance actions.

Water chemistry control plays a key role in reducing the risk of the occurrence of EAC, since it generally has a generic and global mitigation effect, whereas most other countermeasures are rather specific to one component location or material type. In this paper, the role of water chemistry in EAC is briefly illustrated on a purely phenomenological basis by two selected real examples from an ongoing research project at PSI about the effect of chloride transients and of hydrogen water chemistry (HWC) on EAC of low-alloy reactor pressure vessel steels under BWR conditions. 


\section{Materials and Experimental Procedure}

Several different low-alloy, nuclear grade reactor pressure vessel steels of the type $20 \mathrm{MnMoNi} 55,22 \mathrm{NiMoCr} 37$, SA 533 B Cl.1, SA $508 \mathrm{Cl} .2$ and Cl.3 were investigated. The material properties such as steel sulphur content, MnS-inclusion morphology, and susceptibility to dynamic strain ageing, which govern the EAC response in high-temperature water, covered both lower and upper bound material qualities. Usually, $25 \mathrm{~mm}$ thick compact tension $\mathrm{C}(\mathrm{T})$ fracture mechanics specimens (Fig. 1) were manufactured from the forged ingots/ hot-rolled steel plates and then fatigue precracked in air at room temperature.

The time-consuming EAC tests with the pre-cracked specimens were performed in 101 stainless steel autoclaves with integrated electromechanical loading systems, which were attached to sophisticated refreshing high-temperature water loops (Fig. 1). These facilities allow a realistic simulation of the water chemistry and thermo-mechanical loading conditions during BWR power operation. During the experiments all important mechanical (load, pull rod stroke) and environmental parameters at inlet and outlet $\left(\mathrm{O}_{2}, \mathrm{H}_{2}\right.$, conductivity, temperature, pressure, flow) were recorded continuously. The free electrochemical corrosion potential (ECP) of the specimens and the redox potential (platinum probe) were monitored by use of an external Ag/
$\mathrm{AgCl} / 0.01 \mathrm{M} \mathrm{KCl}$ and/or a $\mathrm{Cu} / \mathrm{Cu}_{2} \mathrm{O} / \mathrm{ZrO}_{2}$ membrane reference electrode. Impurities of the water (inlet and outlet) were analyzed by Inductive Coupled Plasma-Atomic Emission Spectroscopy (ICP-AES) and ion chromatography (IC) about four times each test. The crack advance was monitored using the reversed direct current potential drop (DCPD) method with a resolution limit of about $2 \mu \mathrm{m}$. After the tests all specimens were broken open at liquid nitrogen temperature for subsequent fractographical analysis in the scanning electron microscope.

\section{Results and Discussion}

\subsection{Effect of Chloride Transients}

BWR are operated with neutral high-purity water, which contains various amounts of dissolved $\mathrm{O}_{2}, \mathrm{H}_{2} \mathrm{O}_{2}$, and $\mathrm{H}_{2}$ from water radiolysis in the reactor core and $\mathrm{O}_{2}$ and $\mathrm{H}_{2}$ (HWC) additions to the feedwater. Typical $\mathrm{BWR}$ reactor water conditions and the resulting ECP of primary pressure boundary components for normal water chemistry (NWC) and HWC conditions are given in Table 1. Because of the radiolytic decomposition of the reactor coolant in the core and the different partitioning behaviour of the stable radiolytic products between the water and steam phase $\left(\mathrm{H}_{2} \mathrm{O}_{2}\right.$ is virtually non-volatile), the reactor water of $\mathrm{BWR}$ under NWC conditions contains a stoichiometric excess of oxidants $\left(\mathrm{O}_{2}, \mathrm{H}_{2} \mathrm{O}_{2}\right)$ and is therefore sufficiently oxidizing to promote EAC in most structural materials. On the environmental side, EAC in BWR is synergistically controlled by the redox potential (and resulting ECP of the components) and the concentration of harmful anionic impurities like sulphate or chloride in the reactor coolant [2][6]. Nowadays, the concentration of these anionic impurities can be kept on a very low level $<1 \mathrm{ppb}(1 \mathrm{ppb}=$ $1 \mu \mathrm{g} / \mathrm{l})$, usually below the detection limit of ion chromatography.

The EAC behaviour during and after water chemistry transients is of practical relevance because BWR operation inevitably involves periodic short-term variations in water chemistry and ECP. Water chemistry and ECP transients occur during start-up/shut-down and occasionally during steady-state power operation (e.g. ion exchanger resin intrusions, condenser leakages, etc.). Therefore, the EAC crack growth behaviour of different low-alloy reactor pressure vessel steels during and after chloride transients is currently being investigated under simulated BWR/NWC power operation conditions. Furthermore, the adequacy and conservative character of the BWRVIP-60 disposition lines [2] for SCC crack growth in low-alloy steels during and after water chemistry transients is evaluated and assessed in the context of the current US EPRI (Electric Power Research Institute) and German VGB (Vereinigung der Grosskraftwerksbetreiber) BWR water chemistry guidelines (Table 2) [5].

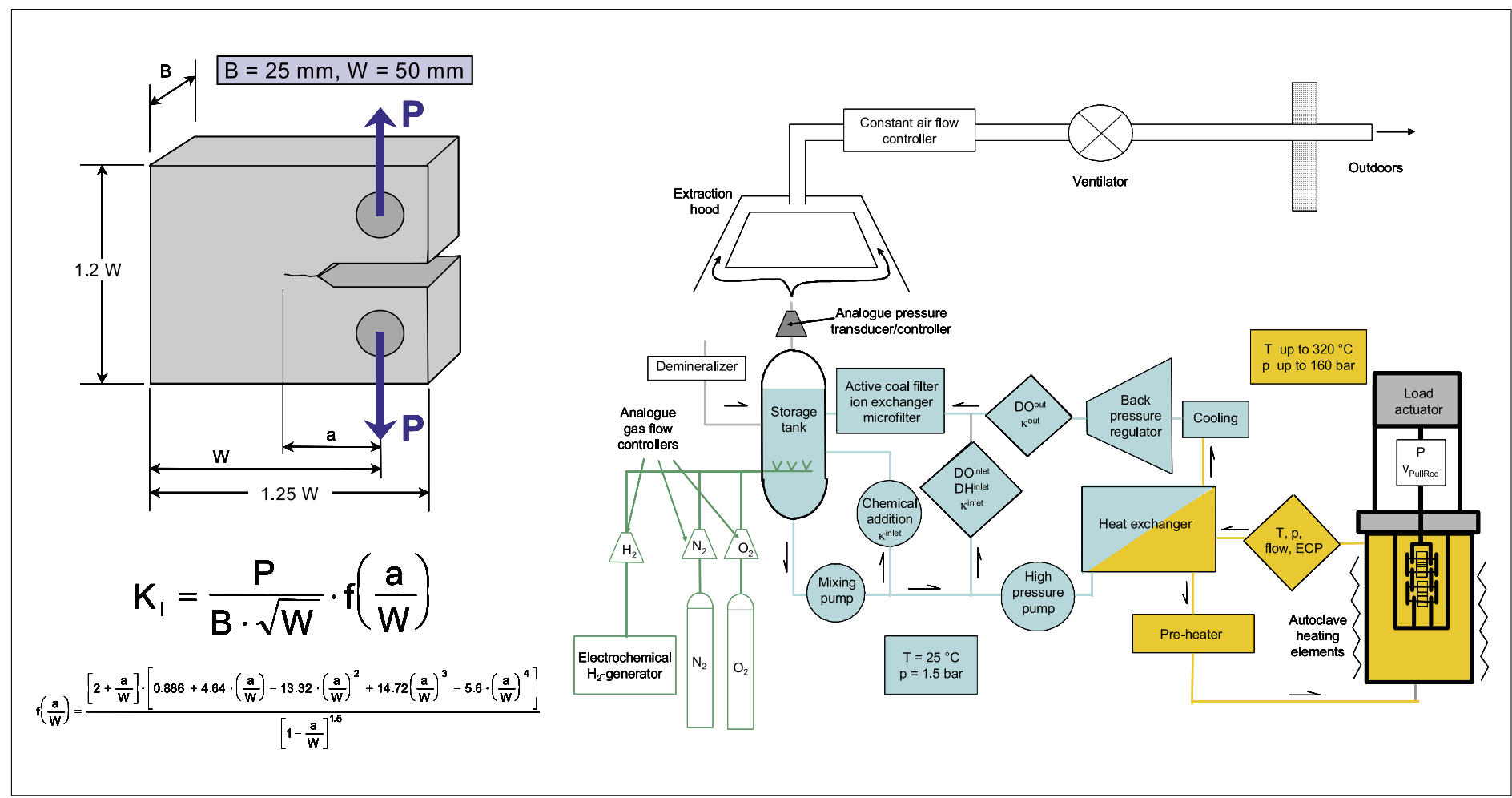

Fig. 1: Pre-cracked compact tension specimen $\mathrm{C}(\mathrm{T})$ and equation for calculation of $\mathrm{K}_{\mathrm{l}}$ (left). Schematic of high-temperature water loop with autoclave and electro-mechanical tensile machine (right) 
Table 1. Typical BWR reactor water conditions under NWC and HWC conditions

Parameter

BWR/NWC

Temperature

Pressure

Flow rate

$\mathrm{pH}_{288^{\circ} \mathrm{C}}$

Conductivity at $25^{\circ} \mathrm{C}$

$\mathrm{Cl}^{-}, \mathrm{SO}_{4}{ }^{2-}$

Composition

$\mathrm{O}_{2}$

$\mathrm{H}_{2} \mathrm{O}_{2}$

$\mathrm{H}_{2}$

ECP (low-alloy steel)

Table 2. Action levels of the EPRI and VGB BWR guidelines for the reactor water during stationary power operation
(Initiation of countermeasures)

EPRI Guideline

$>5 \mathrm{ppb} \mathrm{Cl}^{-} \quad>0.30 \mu \mathrm{S} / \mathrm{cm}$

VGB Guideline

\section{Action Level 1}

\section{Action Level 3}

(Shut-down asap)

$>100 \mathrm{ppb} \mathrm{Cl}^{-} \quad>5.00 \mu \mathrm{S} / \mathrm{cm}$
BWR/HWC

Excess of $\mathrm{H}_{2}$

$<5 \mathrm{ppb}$

$<10 \mathrm{ppb}$

50 to $300 \mathrm{ppb}$
$>5.00 \mu \mathrm{S} / \mathrm{cm}$
$>200 \mathrm{ppb} \mathrm{Cl}^{-}$
In the high-purity $(<1 \mathrm{ppb}$ sulphate and chloride) BWR environment, low-alloy reactor pressure vessel steels generally reveal very low SCC crack growth rates of $<0.6 \mathrm{~mm} /$ year up to relatively high stress intensity factors $\mathrm{K}_{\mathrm{I}}\left(\mathrm{K}_{\mathrm{I}}\right.$ is a measure for the mechanical loading conditions at the cracktip) of $60 \mathrm{MPa} \cdot \mathrm{m}^{1 / 2}[2]$. On the other hand, our current investigations clearly revealed that the addition of very small amounts of chloride as $\mathrm{NaCl}$ or $\mathrm{HCl}$ in the range of 5 to $15 \mathrm{ppb}$ were already sufficient to induce fast SCC crack growth in reactor pressure vessel steels under oxidizing BWR/NWC conditions down to very low stress intensity factors of $20 \mathrm{MPa} \cdot \mathrm{m}^{1 / 2}$ (Fig. 2 and 3).

In constant load tests with periodical partial unloading (to $80 \%$ of maximum load every $12 \mathrm{~h}$ ), acceleration of SCC crack growth was already observed a few hours after the addition of chloride in some cases. The stationary SCC crack growth rates during the chloride transients reached up to $1.5 \mathrm{~mm} /$ day at high chloride levels of $50 \mathrm{ppb}$ and significantly exceeded the BWRVIP-60 SCC disposition line 2 for water chemistry transients for chloride concentrations $\geq 5 \mathrm{ppb}$ (Fig. 4). A modification of the BWRVIP-60 SCC disposition line 2 should therefore be pursued for the case of chloride transients.

After returning to high-purity water, the cracks still grew with the same high crack growth rates for some 10 to $50 \mathrm{~h}$ before a decay of the crack propagation rate was observed. In the case of moderate chloride transients ( $\leq 10 \mathrm{ppb})$, the SCC crack growth rates then dropped again to the same low

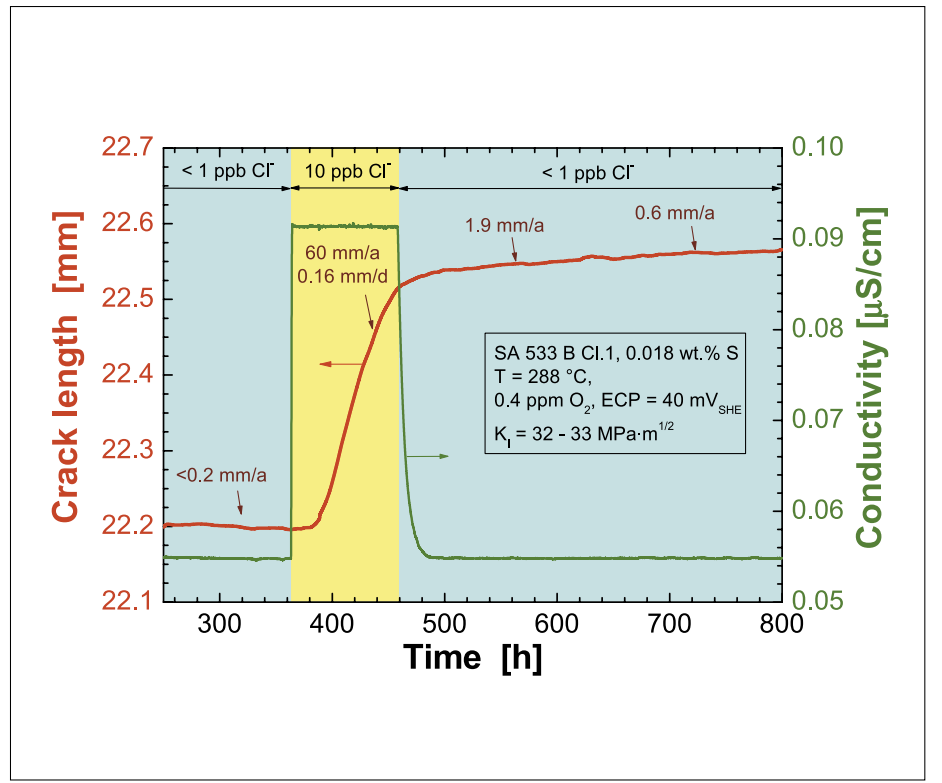

Fig. 2. SCC crack growth before, during, and after a $4 \mathrm{~d}$ chloride transient of $10 \mathrm{ppb}$ (added as $\mathrm{NaCl}$ ) in the reactor pressure vessel steel SA $533 \mathrm{~B} \mathrm{Cl.1}$ $(0.018 \%$ S) under simulated BWR/NWC conditions

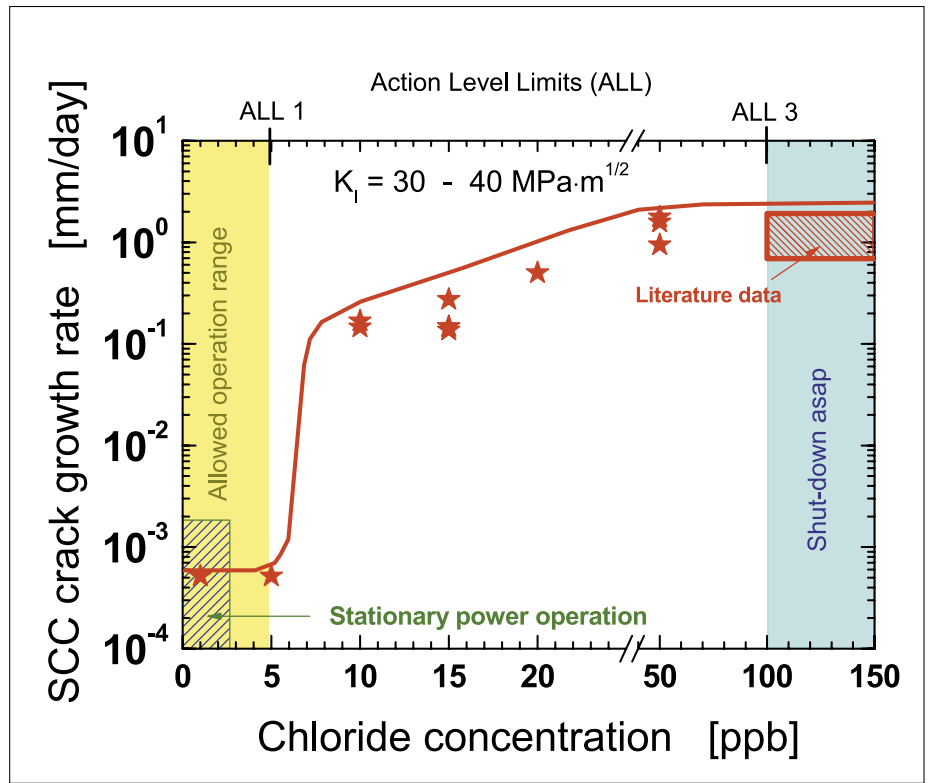

Fig. 3. Effect of chloride concentration on SCC crack growth rate in highsulphur reactor pressure vessel steels under highly oxidizing BWR/NWC conditions $\left(\mathrm{ECP}=+50\right.$ to $+150 \mathrm{mV}_{\mathrm{SHE}}$ ) and comparison with action level 1 and 3 range of the EPRI water chemistry guidelines. These investigations indicate a critical chloride concentration in the range of 5 to $10 \mathrm{ppb}$ slightly above the action level limit 1 for the investigated reactor pressure vessel steels in the stress intensity factor range of 30 to $40 \mathrm{MPa} \cdot \mathrm{m}^{1 / 2}$. 


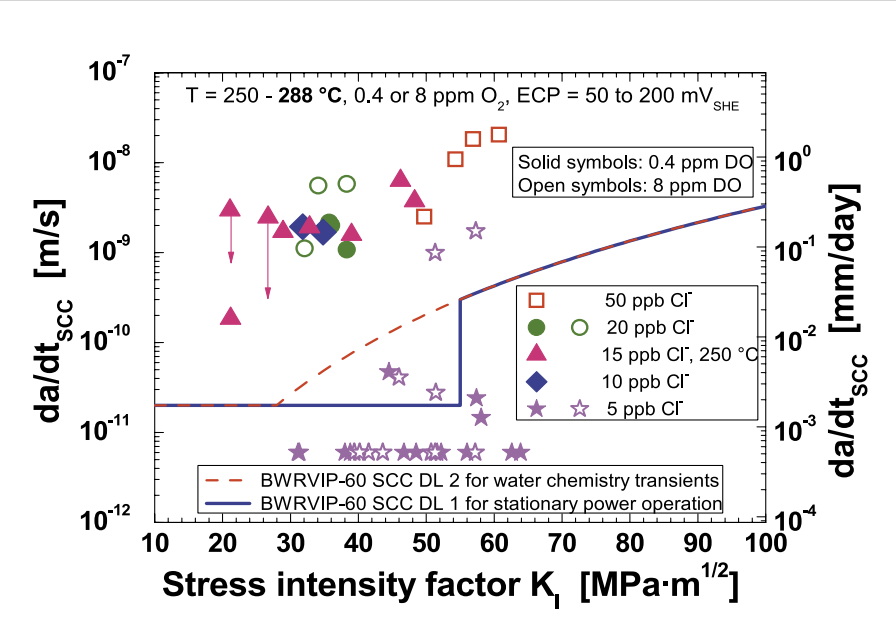

Fig. 4. Comparison of SCC crack growth rates during chloride transients under BWR/NWC conditions with the corresponding BWRVIP-60 DL 2 and 1 for water chemistry transients and stationary power operation. Under highly oxidizing conditions the BWRVIP-60 DL 2 is not conservative for chloride contents $\geq 5 \mathrm{ppb}$.

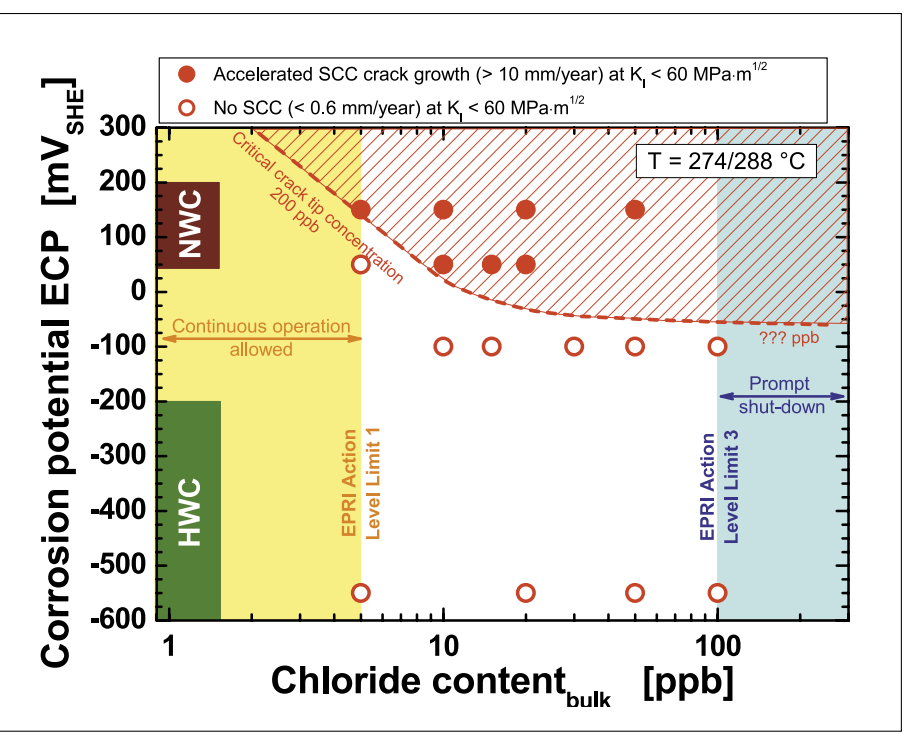

Fig. 5. Synergistic effect of corrosion potential ECP and chloride content on the onset of fast SCC crack growth in reactor pressure vessel steels under BWR conditions and comparison with the typical conditions during stationary power operation. Increasing chloride tolerance with decreasing ECP.

values as in high-purity water $(<0.6 \mathrm{~mm} /$ year) and below the BWRVIP-60 disposition line 1 for transient-free, stationary power operation within some few further hundreds of hours. After severe ( $\geq 20 \mathrm{ppb})$ and prolonged $(>100 \mathrm{~h}$ ) chloride transients sustained, fast SCC crack growth was observed for at least $1000 \mathrm{~h}$.

The critical chloride concentration for the onset of fast SCC significantly increased with decreasing ECP. This result thus indicates a significantly higher impurity tolerance at lower potentials (e.g. in the feedwater piping system) or under HWC conditions (Fig. 5).

Although the observations are only valid for long pre-existing cracks where enrichment of chloride in the crack-tip electrolyte by ion migration occurs [6] and may therefore not be directly transferred to defectfree component surfaces, they clearly show that much smaller chloride concentrations than believed so far can have a tremendous impact on EAC and that it is essential to maintain a low impurity level, in particular at high ECP under NWC conditions. The possibly short incubation period for acceleration of SCC in combination with the very high SCC crack growth rates under static loading conditions of up to $1.5 \mathrm{~mm} /$ day and possible long-term effects, at least after severe $(\geq 20 \mathrm{ppb})$ and prolonged $(>100$ h) chloride transients, raise some concern for severe chloride transients under BWR/ NWC conditions. The frequency and extent of chloride transients above the EPRI action level limit 1 should therefore be reduced to the lowest possible level by adequate countermeasures and immediate actions.

\subsection{Mitigation Effect of HWC on EAC of Low-Alloy Steels}

The EAC susceptibility and crack propagation rates of all structural materials strongly increase with increasing ECP in high-temperature water [6]. The reduction of ECP by hydrogen injection (HWC) [7][8], alone or in combination with noble metal chemical addition (NMCA) [8][9], has been proven to be a powerful tool for mitigating SCC in stainless steel and $\mathrm{Ni}$ base alloys and a growing number of BWR now apply the HWC or NMCA technology worldwide. The effect of HWC or NMCA on EAC of low-alloy steels has hardly been investigated so far, although a very beneficial effect can be expected. Since the Swiss BWR Mühleberg is using the HWC/NMCA technology and the BWR Leibstadt will implement the HWC technology in 2006 , the effect of HWC on the low-frequency corrosion fatigue and SCC crack growth behaviour of low-alloy steels is therefore currently under investigation at PSI.

The mitigation effect of HWC is primarily evaluated under those critical and unfavourable system parameter combinations which resulted in accelerated corrosion fatigue and SCC crack growth significantly above the ASME XI reference fatigue [2] and BWRVIP-60 SCC crack growth curves [2] under NWC conditions in previous studies [2][10]. For this reason, the EAC crack growth behaviour of low-alloy steels is currently being studied for these specific critical parameter combinations during a change from oxidizing NWC to reducing HWC and back to oxidizing NWC conditions. The applied water chemistry and resulting electrochemical conditions are summarized in Table 3.

Table 3. Simulated NWC and HWC conditions

\begin{tabular}{|c|c|c|c|c|}
\hline & $\begin{array}{l}\mathrm{O}_{2} \\
\text { [ppm] }\end{array}$ & $\begin{array}{l}\mathrm{H}_{2} \\
\text { [ppm] }\end{array}$ & $\begin{array}{l}\text { ECP } \\
{\left[\mathrm{mV}_{\text {SHE }}\right]}\end{array}$ & $\begin{array}{l}\text { Redox } \\
{\left[\mathrm{mV}_{\mathrm{SHE}}\right]}\end{array}$ \\
\hline \multirow{2}{*}{ NWC } & 0.4 & 0 & +40 to +60 & +250 \\
\hline & 8 & 0 & +130 to +170 & +290 \\
\hline HWC & 0 & 0.15 & -550 to -620 & -530 \\
\hline
\end{tabular}




\subsubsection{Mitigation of Corrosion Fatigue Crack Growth}

The current ASME XI wet reference fatigue crack growth curves conservatively covered the corrosion fatigue crack propagation lab data under most simulated BWR/ NWC conditions and parameter combinations, and were usually only exceeded under some very specific BWR plant conditions. In particular under highly oxidizing BWR/ NWC conditions $\left(+50 \leq \mathrm{ECP} \leq 200 \mathrm{mV}_{\mathrm{SHE}}\right.$, 0.4 to $8 \mathrm{ppm} \mathrm{O}_{2}$ ), the current ASME XI wet fatigue crack propagation curves could be significantly exceeded for all investigated materials in the temperature range between 150 and $288^{\circ} \mathrm{C}$ by cyclic fatigue loading at low frequencies $v \leq 5 \cdot 10^{-2} \mathrm{~Hz}$ and stress intensity factor amplitudes $\Delta \mathrm{K} \geq 2 \mathrm{MPa} \cdot \mathrm{m}^{1 / 2}$. Corrosion fatigue tests at PSI with $\mathrm{NWC} \rightarrow$ $\mathrm{HWC} \rightarrow$ NWC-transients always revealed a significant drop of the corrosion fatigue crack growth rates (by a factor of 10 to 50) under these critical low-frequency cyclic loading conditions $\left(\leq 5 \cdot 10^{-2} \mathrm{~Hz}\right)$ a few hours after adding hydrogen and changing to reducing conditions $\left(<-200 \mathrm{mV}_{\mathrm{SHE}}\right) .10$ to $50 \mathrm{~h}$ after returning to oxidizing NWCconditions, the corrosion fatigue crack propagation rates again reached the same high values as before the HWC-transient. An example of this behaviour is shown in Fig. 6.

In Fig. 7, the stationary corrosion fatigue crack propagation rates $\Delta \mathrm{a} / \Delta \mathrm{N}_{\mathrm{CF}}$ (crack advance per fatigue cycle) during NWC and HWC phases under low-frequency $\left(5 \cdot 10^{-4}\right.$ to $4 \cdot 10^{-2} \mathrm{~Hz}$ ) fatigue loading conditions are compared to the corresponding ASME XI reference fatigue crack growth curves. At these low loading frequencies, $\Delta \mathrm{a} / \Delta \mathrm{N}_{\mathrm{CF}}$ significantly exceeded the ASME XI wet reference fatigue crack growth curve under NWC conditions, but dropped well below this curve under HWC conditions.

\subsubsection{Mitigation of SCC Crack Growth}

Previous studies in high-purity BWR environment at temperatures of 274 and $288^{\circ} \mathrm{C}$ revealed a very low SCC susceptibility and very low SCC crack growth rates of $<0.6 \mathrm{~mm} /$ year in reactor pressure vessel steels up to high stress intensity factors $\mathrm{K}$ of $60 \mathrm{MPa} \cdot \mathrm{m}^{1 / 2}$ and basically confirmed the conservative character of the BWRVIP60 SCC disposition line 1 for SCC crack growth under transient-free, stationary BWR power operation conditions [2]. On the other hand several critical parameter combinations could be identified which can result in accelerated SCC crack growth (>3 mm/year) well above the BWRVIP-60 lines. The disposition line 1 was exceeded in case of weld heat-affected zone materials with a high hardness of $350 \mathrm{HV} 5$ and a high sulphur content or at intermediate temperatures $\left(180\right.$ to $270{ }^{\circ} \mathrm{C}$ ) in reactor pressure vessel steels with a distinct susceptibility to dynamic strain ageing. The BWRVIP-60 disposition line 2 for water chemistry and load transients was significantly exceeded in the case of chloride transients $\geq 5 \mathrm{ppb}$ ( $\geq$ EPRI action level 1) and in case of very small superimposed load fluctuations at high load ratios (ratio of minimum to maximum load) $R \geq 0.95$ (ripple loading).

Similarly to the corresponding corrosion fatigue tests, the preliminary $\mathrm{NWC} \rightarrow$ $\mathrm{HWC} \rightarrow$ NWC-transient SCC experiments under these critical parameter combinations always revealed a significant drop of the SCC crack growth rates by a factor of at least 10 (up to 1000 under extreme situ- ations) a few hours after adding hydrogen and changing to reducing conditions $(<-200$ $\left.\mathrm{mV}_{\mathrm{SHE}}\right)$. The SCC crack propagation rates generally dropped below the corresponding BWRVIP-60 disposition lines under HWC conditions. Under static and ripple loading conditions, the SCC crack growth rates stayed on the very low HWC-level after returning to oxidizing NWC-conditions for the remaining test time of up to $1000 \mathrm{~h}$.

In Fig. 8, the SCC crack propagation rates during chloride transients of 5 and $50 \mathrm{ppb}$ under static loading conditions at a stress intensity factor $\mathrm{K}_{\mathrm{I}}$ of $58 \mathrm{MPa} \cdot \mathrm{m}^{1 / 2}$ under NWC and HWC conditions are compared to the corresponding growth rates in high-purity water $\left(<1 \mathrm{ppb} \mathrm{Cl}^{-}\right)$. These investigations clearly demonstrated the higher impurity tolerance under HWC conditions. The critical chloride concentration for the onset of accelerated SCC crack growth $(>1$ $\mathrm{cm} /$ year) at stress intensity factors $\mathrm{K}_{\mathrm{I}}<60$ $\mathrm{MPa} \cdot \mathrm{m}^{1 / 2}$ under HWC conditions is expected to lie above $100 \mathrm{ppb}$ and is therefore significantly higher than the relatively low values of 5 (at $+150 \mathrm{mV}_{\mathrm{SHE}}$ ) to $10 \mathrm{ppb}$ (at $\left.+50 \mathrm{mV}_{\mathrm{SHE}}\right)$ at high potentials under NWC conditions.

So both under static or cyclic loading conditions, the application of HWC always resulted in a significant reduction of SCC and low-frequency corrosion fatigue crack propagation rates by at least one order of magnitude with respect to NWC conditions. A few hours after changing from oxidizing NWC to reducing HWC conditions, the growth rates generally dropped below the corresponding disposition curves. HWC is therefore a promising and powerful mitigation method for EAC in low-alloy steels under these critical parameter combinations.

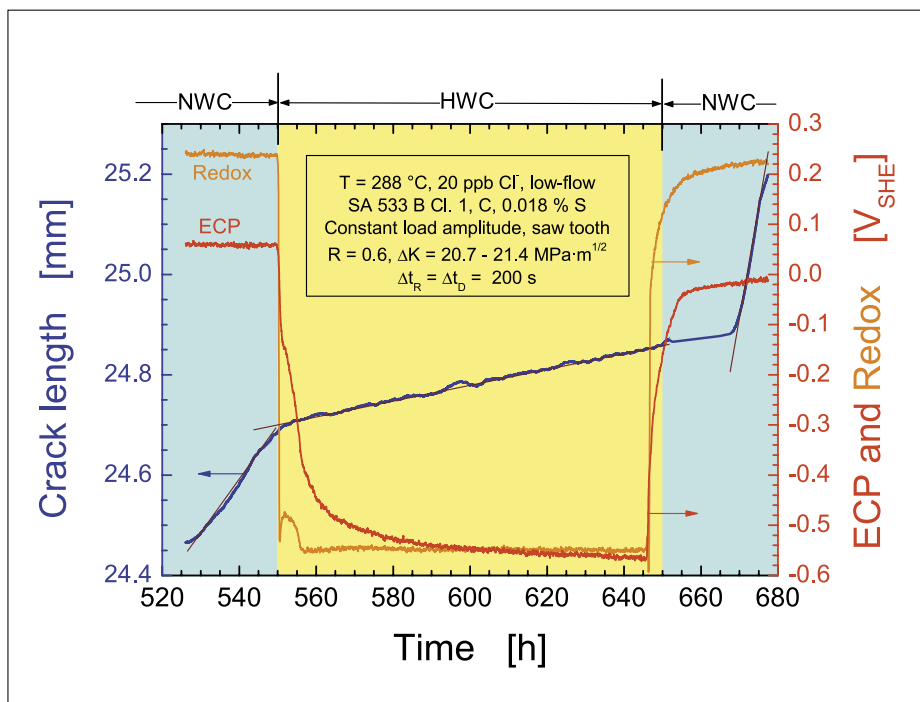

Fig. 6. Example of low-frequency corrosion fatigue crack growth during a $\mathrm{NWC} \rightarrow \mathrm{HWC} \rightarrow \mathrm{NWC}$-transient

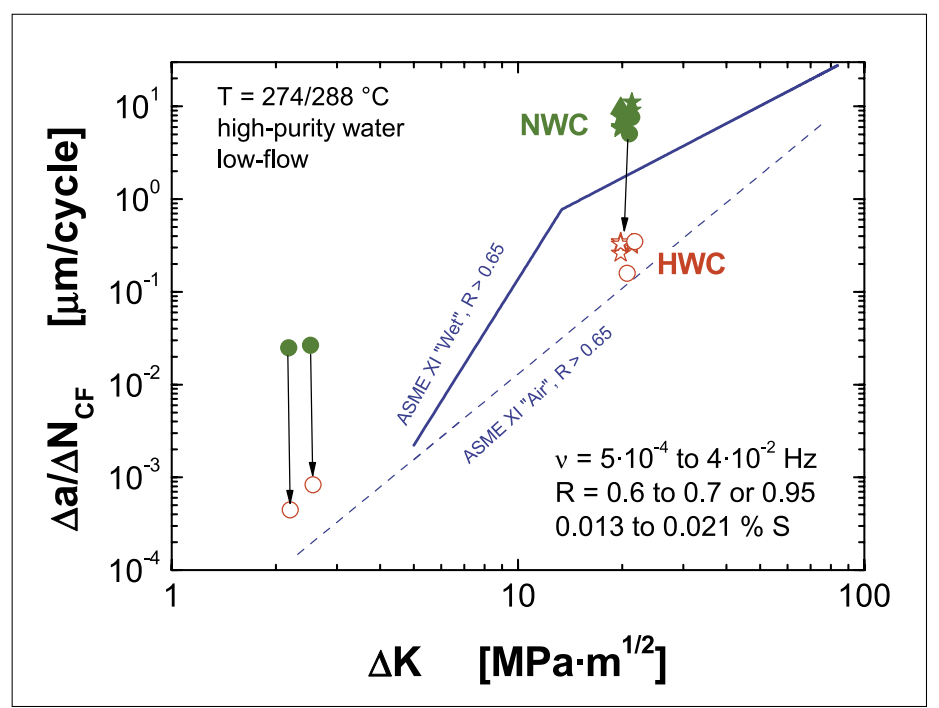

Fig. 7. Comparison of stationary corrosion fatigue crack propagation rates $\Delta \mathrm{a} / \Delta \mathrm{N}_{\mathrm{CF}}$ under low-frequency $\left(5 \cdot 10^{-4}\right.$ to $\left.4 \cdot 10^{-2} \mathrm{~Hz}\right)$ fatigue loading conditions during NWC and HWC phases with corresponding ASME XI reference fatigue CGR for the specified loading conditions 


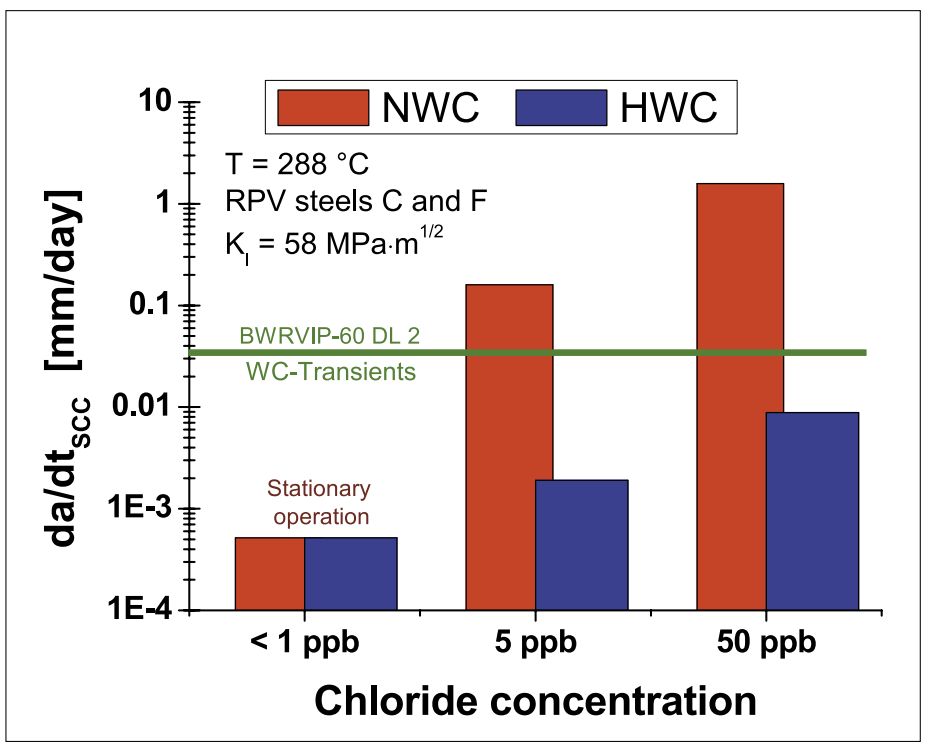

Fig. 8. SCC crack growth rates during chloride transients under NWC $\left(\mathrm{ECP}=+50\right.$ to $\left.+150 \mathrm{mV}_{\mathrm{SHE}}\right)$ and $\mathrm{HWC}\left(\mathrm{ECP}=-620 \mathrm{mV}_{\mathrm{SHE}}\right)$ conditions and comparison to typical propagation rates in high-purity water

\section{Summary and Conclusions}

EAC in structural materials is one of the most important degradation and ageing mechanism in BWR and may seriously affect plant availability and economics. On the environmental side, EAC in BWR is synergistically controlled by the redox potential and concentration of specific harmful anionic impurities in the reactor coolant. The important role of water chemistry control in reducing the EAC risk in LWR has been illustrated on a phenomenological basis by current research results on the effect of chloride transients and hydrogen water chemistry on the EAC crack growth behaviour of low-alloy reactor pressure vessel steels under BWR conditions. The combination of keeping the concentration of specific harmful anionic impurities like sulphate and chloride at a very low level $(<1$ $\mathrm{ppb}$ ) and of reducing the redox potential of the environment and ECP of the structural materials, e.g. by hydrogen injection (HWC or NMCA), is a very powerful tool for mitigating EAC crack growth in lowalloy steels.

\section{Acknowledgments}

This work has been performed within the RIKORR-I/II projects at PSI. The financial support for this work by the Swiss Federal Nuclear Safety Inspectorate (HSK), the Swiss Federal Office of Energy (BFE), and Swiss Utilities (Swissnuclear) is gratefully acknowledged. Thanks are also expressed to U. Ineichen, B. Gerodetti, U. Tschanz, and E. Groth (all PSI) for their experimental contribution to the projects.
[1] R.H. Jones, R.E. Ricker, in 'Stress Corrosion Cracking - Materials Performance and Evaluation', Ed. R.H. Jones, ASM International, Materials Park, Ohio, USA, 1992, 1-40.

[2] H.P. Seifert, S. Ritter, J. Hickling, Power Plant Chemistry 2004, 6, 111-123.

[3] R. Kilian, A. Roth, Materials and Corrosion 2002, 53, 727-739.

[4] P. Scott, 'An Overview of Materials Degradation by Stress Corrosion in PWRs', Proc. EUROCORR 2004, CD-ROM, Nice, France, September 12-16, 2004.

[5] S. Ritter, H.P. Seifert, Power Plant Chemistry 2004, 6, 748-760.

[6] P. Andresen, L. Young, 'Characterization of the Roles of Electrochemistry, Convection and Crack Chemistry in SCC', Proc. 7th International Conference on Environmental Degradation of Materials in Nuclear Systems - Power Reactors, NACE, 579-596, 1995.

[7] C.C. Lin, Nuclear Technology 2000, 130, 59-70.

[8] F. Sarrot, Chimia 2005, 59, 923.

[9] S. Hettiarachi, 'WR SCC Mitigation Strategies and Their Effectiveness', Proc. 11th International Conference on Environmental Degradation of Materials in Nuclear Systems - Power Reactors, 477-485, CD-ROM, ANS/TMS/NACE, Skamania Lodge, Stevenson Washington USA, August 10-14, 2003.

[10] H.P. Seifert, S. Ritter, 'Mitigation Effect of Hydrogen Water Chemistry on SCC and Low-Frequency Corrosion Fatigue Crack Growth in Low-Alloy Steels', Proc. 12th International Conference on Environmental Degradation of Materials in Nuclear Systems - Power Reactors, 477-485, CD-ROM, ANS/TMS/NACE, Snowbird, Utah, USA, August 14-18, 2005. 